\title{
Improving Sustainable Mobility through Modal Rewarding: The GOOD_GO Smart Platform
}

\author{
ANTONIO PRATELLI*, MASSIMILIANO PETRI*, ALESSANDRO FARINA*, \\ REGINALD R. SOULEYRETTE** \\ *Logistics Center of the University of Pisa, Via dei Pensieri 60, 57100 Livorno \\ ITALY \\ ** College of Engineering, 351 Ralph G. Anderson Building, Lexington, Kentucky 40506 \\ USA
}

\begin{abstract}
Private car mobility registers today a high accident rate and around $70 \%$ of the overall $\mathrm{CO} 2$ emissions from transport were generated by road mode split (European Commission, 2016). Moreover, in urban areas they occur $38 \%$ of the overall fatalities from road transport, and $23 \%$ of the overall $\mathrm{CO} 2$ emissions (European Commission, 2013). As a result, a modal shift of at least a part of passenger transport in urban areas, from private car to sustainable transport systems is desirable.

This research aims to promote sustainable mobility through two mutually reinforcing "main actions": firstly, there is a rewarding Open-Source platform, named as GOOD_GO; secondly, there is the SW/HW system connecting to the wide world of private and/or shared bicycles. Through the GOOD_GO platform Web portal and App, a user enters a so called 'social rewarding game' thought to incentive sustainable mobility habits, and gets access to the second item consisting of a system to disincentive bike-theft and based on the passive RFID technology.

The low-cost deterrent bike-theft and bike monitoring/tracking system is functional to bring a big number of citizens inside the rewarding game.

In 2018, a pilot test has implemented in the city of Livorno (Tuscany, It), and it involved around 1,000 citizens. Results were quite encouraging and today, the cities of Livorno, Pisa and Bolzano will enlarge the incentive system both to home-to-school and home-to-work mobility. The Good_Go platform is an actual M-a-a-S (Mobility-as-a-Service) application, and it becoming a Mobility Management decision system support, jointly with the opportunity of organizing more incentive tenders and rewarding systems types.
\end{abstract}

Key-Words: - Rewarding sustainable mobility; M-a-a-S applications; Mobility Management; bike mode monitoring web-platform.

Received: October 20, 2019. Revised: March 10, 2020. Accepted: April 12, 2020. Published: April 24, 2020.

\section{Introduction}

Private car mobility registers today a high accident rate and around $70 \%$ of the overall $\mathrm{CO} 2$ emissions from transport were generated by road mode split [1]. Moreover, in urban areas they occur $38 \%$ of the overall fatalities from road transport, and $23 \%$ of the overall $\mathrm{CO} 2$ emissions [2]. As a result, a modal shift of at least a $p$ art of passenger transport in urban areas, from private car to sustainable transport systems is desirable. Several policies have been adopted in the EU in this direction [3]. Moreover, bike-sharing solutions has a high maintenance costs and, especially in medium size cities, this limits its application.

This project has been developed in order to improve at first the private bike mobility [4] and linked to it a 11 other sustainable mobility modes present in urban areas (public transport, car-pooling, electric car-sharing, etc.). However, several factors, currently, limit the bike development. A first factor is the high number of bike thefts in Italy but also in the rest of Europe: in Florence, $40 \%$ of complaints for thefts regard bicycles. Some countermeasures have already been applied but results have been not relevant. A second factor is the low attitude to bicycles use, even for short trips and the culture of private car usage. The change of mobility attitudes is encouraged also by the European Commission, through the adoption of rewarding policies. However, currently only a few rewarding policies have been performed on occasional basis; moreover, they have never been applied to private bikes.

The research project regards the development of a 'space of services' for sustainable mobility users linked to ITS sensors and an ICT social rewarding platform called GOOD_GO capable of: 
- monitoring systematically bicycle trips and all the other transport modes by using an APP for smartphone;

- creating secure areas for private bike parking;

- finding stolen bicycles;

- rewarding people who perform sustainable trips in the city;

- generating financial resources for public administration through the annual subscriptions.

The following section is devoted to present the state of art about mobility rewarding projects and softwares. In the third section it is described the Good Go platform and the first application in the real living lab tested in Livorno (Tuscany, It). Finally, some conclusions and future developments are discussed.

\section{Mobility Rewarding Strategies and Softwares: The State of Art}

Several policies aimed at disincentivizing less sustainable transport modes have been implemented; these policies are addressed as accessibility restriction ones, and are distinguished in: Access Restriction Schemes (ARS) and Low Emission Zones (LEZ).

These policies have generally a negative impact on citizens, while, as reported in EPOMM [5] and Dogteron et al. [6], rewards are well accepted. In Tillema et al. [7] rewarding and penality systems are compared; moreover these authors show that a theoretical pricing solution should make each user pay the cost that the society has to bear because of his mobility habits.

De Palma et al. [8] presented a quantitative comparison among rewarding systems (especially Tradable Mobility Permits, TMPs) and penalty systems on a simulated road network. This study has foreseen the search of the 'social optimum', i.e. the condition in which the total welfare is maximized. In Weitzmann [9] it is reported that pricing and rewarding systems are equivalent when uncertainty is zero. In De Palma et al. [8] the uncertainty is modelized by a Logit model; if the uncertainty is not zero, TMP systems are those whose maximize the overall welfare and consumer surplus.

The preference of road users toward the rewarding systems was highlited also by Parag et al. [10]. These last researchers shown that the impact of rewarding systems, in terms of decrease of carbon emissions of a p opulation sample, is greater than that of penalty ones.

Among rewarding measures, several policies and actions could be considered. The fare system of local public transport comprises reward measures, for example the weekly and monthly tickets incentivize the use of public transport for systematic home - work trips.

Rewarding actions and measures must be based on a set of cornerstones, i.e.:

1. Definition of targets and general indicators: e.g., the emission reduction targets and the indicators for the impacts monitoring.

2. Setting of incentives and rewards: for example, identification of target groups and of the types of rewards most suited to their specific interests, such as discounts on public transport or on tickets for museums, cinemas, etc.

3. Setting of the ways to measure the behavior habits. All rewarding systems refer to different monitoring technologies, which could be ITS installed on the roads or on $\mathrm{v}$ ehicles, or smartphone apps or other 'soft' technologies capable of providing information on trips performed by the users. These systems are also used to calculate the amount of scores gained by each user and the impacts of user mobility habits.

4. Distribution of the incentives to users: it could follow a 'push' and/or 'pull' mechanism: in the first case the reward is automatically credited to the user, while in the second case the reward is requested directly by the user in a market place integrated in a web platform.

Rewarding systems could be classified as follows:

1. systems which only incentivize sustainable mobility habits: they are usually simply discounts on a given transport mode;

2. systems with balanced reward credits: they derive from the trade-off of sustainable and not sustainable transport modes.

3. mobility tradable credit scheme: which is an evolution of the previous two rewarding schemes.

A further category of rewarding systems could be added to the previous ones: it comprises those systems which increase the awareness on user mobility habits. These are:

- information systems on the various alternative transport modes;

- feedback and self-monitoring systems;

- use of social networks and share of mobility best practices.

The first type of rewarding systems, which simply incentivizes sustainable mobility habits, focuses on sustainable user habits but neglects not sustainable ones. As a result, a user which performs a large number of trips, but only a minor part of 
them by sustainable transport modes, collects a greater number of credits than a ser which performs a small number of trips, all by sustainable transport modes.

The second type of rewarding systems balances trips performed by sustainable and by not sustainable transport modes. Therefore, a user gains credits when travelling by a su stainable transport mode, and looses credits when travelling by a not sustainable transport mode.

These two types of rewarding systems are able to incentivize the sustainable mobility, but they are not enough to reach the targets of public administrations. Indeed, it is necessary to create a centralized system which manages and monitors the present and future impact of rewarding policies. The Mobility Credit Market (MCM) allows to create such control and monitoring system and manages the mobility demand, but leaves to the citizen a greater freedom than the accessibility restriction measures. The MCM is also based on given quantitative targets related to the Sustainable Environmental Footprint, i.e. it imposes a threshold for each externality (energy consumption, $\mathrm{CO}_{2}$ production, etc.).

The main fundamental principles of MCM are:

- definition of targets and measures to assess the total environmental footprint, considering all externalities connected to transport, i.e. pollutant emissions, congestion, noise, accidents;

- distribution of the initial credit budget: the total environmental footprint must be converted in a total credit budget, to distribute to the population and to transport operators;

- establishment of rules for credit consumption: the credit consumption should be based on mobility behavior factors such as: transport modes, characteristics of vehicles, vehicle dimensions, emission class of vehicles' engine, availability of alternative transport modes, etc.;

- credit exchange: it allows travelers having a negative credit balance to acquire extra credits by users having a positive balance. The total number of credits remains the same: this means that a threshold to the global environmental footprint level is fixed. This type of control is completely missing in the first and in the second typology of rewarding systems.

As a result, in the MCM, users travelling by nonsustainable modes spend all their credits, therefore, if they wish to continue travelling by car, then they need to purchase some credits from the other users.

\subsection{Cases of Study and Best Practices}

Cases of study of rewarding measures are often test cases and experimentations funded by European projects or proposed by municipalities. These cases of study are generally limited in number and often concern uni-modal transportation modes: for example, rewards to citizens travelling by bicycle, or fully free access to public transport. In other cases, no real rewards are provided to users but simply refunds of expenses [11].

Some cases of study make reference to The Netherlands, where the government, after a policy of road pricing, strongly criticized by citizens, has experimented new demand management systems based on rewards [12].

\subsubsection{The Spitsmijden Project - The Netherlands} The Spitsmijden ('to avoid rush hour') project represents a case of study of rewarding systems aimed at modifying mobility habits. In this project, begun in 2006, rewards try to disincentivize the displacements in the morning peak hour; moreover this project is aimed at analyzing the impact of rewards on the change of commuters mobility habits. This project consists of a set of experiments on a sample of 341 volunteers living in the city of Zoetermeer and commuting to The Hague for work or study reasons. These volunteers received rewards if they avoided travelling on $t$ he motorway Zoetermeer - The Hague from 7:30 to 9:30, by using public transport or by moving in a different time period of the day.

In the first phase of this project, volunteers had to complete some questionnaires about their socioeconomic characteristics and mobility habits [13]. The second phase of the project consisted of the experimentation itself, which lasted 13 weeks. In the third phase, the project participants answered some general questions about the experiment.

This project at first was very successful, because, thanks to rewards, between $20 \%$ and $50 \%$ of participants have changed their mobility habits, especially the time of departure and the path followed; more rarely the transport mode. But, after the end of the project, the great majority of users returned to their old mobility habits. Another problem was the heaviness of rewards for the public administration.

As shown in Tillema et al. [12], high economic rewards are a significant cost for the public administration and do not have further impacts on the user mobility habits: an acceptable amount of reward, which significantly impacts on user mobility habits and is not too expensive for the 
public administration, is, for example, from 1.5 to 3 $€ /$ day.

\subsubsection{The follow-ups of Spitsmijden}

Starting from the Spitsmijden project results, three new projects were developed, namely SpitsScoren, Spitsvrij and a second Spitsmijden project in other Netherland cities.

The SpitsScoren project was the biggest one, with a budget of over 9 million $€$, and it aimed at reducing the congestion on the road corridor constituted of the A15 motorway and parallel roads, which connect the cities of Vannplein and Rozenburg (Khademi et al. [12]). The project has reduced by $7 \%$ traffic flows in the morning peak hour. About 2,000 users were detected who performed habitual use of the road corridor and they were involved in the test. The test lasted three years, from 2010 to 2012. A smartphone was provided, with a pre-installed app, where each participant had to write down the mobility preferences for the following day, for example: go to work before the peak hour, use public transport, use a slow transport mode (e.g. bicycle), use car-pooling, use alternative paths external to the corridor. The GPS positioning system based on smarphones and videocameras were used to control the effective choices performed by users. A mixed Logit model [12] has been applied to analyze user mobility choices. This analysis has shown that the utility of the 'not changing behavior' alternative increased during the three years of the project, while the utility of the 'drive before or after the peak period' alternative decreased. As a r esult, it seems that in the long period the effect of incentives decreases.

\subsubsection{The 'Travel Smart Rewards' Programme in Singapore}

The Programme 'Travel Smart Rewards' in Singapore encourages commuters, through cashback, to avoid travelling in the peak hours or to travel by public transport modes. The 'Travel Smart' initiatives include free trips on trains from stations of satellite cities to Singapore and vice versa before 07:45 AM. Moreover, commuters were assigned some scores, according to the amount of time they travel by train and according to the time of the day when they commute. In addition, some companies took part to the Programme, by allowing to workers more flexible working times, or the possibility to work staying at home. Within this initiative, the app 'Travel Smart Rewards' was developed, which is described in the following of this paper.

\subsubsection{The Opti-LOG Project (Italy, Lombardia Region) and other Rewarding Projects Applied to City Logistics}

Funded by the Lombardia Region, in the sector of Smart Cities and Communities, the project OptiLOG promotes and tests innovative solutions of planning and management of last-mile logistics [16]. Opti-LOG actually acts only on city logistics, but with positive impacts on the air quality and on road congestion. In this project, a software platform was developed, with several functionalities, such as the booking of loading/ unloading bays, the tracking of distributors' freight vehicles, the coordination of such vehicles in order to achieve a $\mathrm{m}$ ajor sustainability in delivery operations. The coordination of freight delivery vehicles allows to aggregate the demand and increase the freight vehicles load factors, thanks to the collaboration of stakeholders. Freight transport companies are rewarded for: the usage of low emission vehicles (such as cargo bikes or electric vehicles), a high load factor of freight vehicles, the use of low emission fuels, the use of 'intelligent' time windows for performing deliveries, the use of the vehicle routing optimization system provided by the platform. On the other hand, the administration has offered to the most 'virtuous' drivers the access to LTZ zones or the use of loading/unloading bays.

Other projects applying the rewarding systems to city logistic are: SmartWay, which incentivizes efficient supply chain choices in the U.S., and Green Freight Europe, which performs the same in Europe. Finally, the Lean and Green Programme establishes an award for companies which improve the sustainability of their distribution trips.

\subsubsection{The Project Sharing Cities}

The Sharing Cities research project, funded by Horizon 2020 in 2015, is applied to three 'leader' cities, Milan, London and Lisbon, and to three 'follower' ones, i.e. Warsaw, Bordeaux and Burgas.

This project creates new digital services for citizens, to incentivize their sustainable behaviour. Companies receive rewards for ecological distribution, while citizens are rewarded for reduction in energy consumption for houses, waste differentiation and green mobility behavior.

The rewarding system is based on a marketplace in which rewards can be reserved. Citizens travelling by bicycle, or using public transport, car sharing and car pooling, receive credits which provide them free bus tickets and vouchers for shopping. 
Rewards provided by the public administrations to citizens include: free public transport tickets, free tickets for museums and cultural heritages.

Rewards provided by public administrations to companies include: rewards for green procurement, discounts on the energy fares, free public transport tickets, free publicity for companies' products.

Rewards provided by companies to citizens include discounts on products.

The system is based on an app for smartphone, which collects all these credits. The public administration has to decide the amount of credits to assign to each mobility behavior, the rewarding thresholds and the final targets.

\subsubsection{The Project SUNSET}

The project SUNSET (Sustainable Social Network SErvices for Transport) has been funded within the FP7 of the European Commission; it started in 2011 and ended in 2014. In this project three Living Labs were established in three cities: Enschede (NL), Gothenburg (SE) and Leeds (UK). These Living Labs have involved the following actions:

- optimization of urban mobility by using ICT services which provide the 'best rewards' in the 'best moments';

- measurement of mobility behaviors using the sensors included in the app, together with data collected on the field;

- monitoring of the real time impact of rewards towards the sustainability targets predefined by the public administration;

- investigation of which rewards are most effective for each target group and how they can be offered by the various stakeholders.

The types of incentives offered by SUNSET are the following:

1. Real time travel information: Personalized information on transportation alternatives has led, in some scenarios, to a decrease in the usage of private car (Fuji and Taniguchi [18]). This technique, called Travel Feedback Program (TFP), is very common in Transport Demand Management. TFP could provide: general real time mobility information (for all users), and personalized mobility information (different from a u ser to another) based on users' travel diaries.

2. Feedback and self-monitoring program: The population is rarely aware of the consequences of their mobility habits. Some studies performed in Gouda (NL) (Tertoolen et al. [20]) show that monitoring programs must be accompanied by an economic and environmental feedback. In brief, people do no $t$ want to adopt low impact behaviors for the collective interest, but they do that if also other people change their behavior.

3. Rewards and credits: The behavioral rewards model analyzed by Fogg [21] provide several positive effects. Fogg states that changing mobility habits requires much effort, therefore rewards are essential in order of providing to users enough motivations.

4. Social networks: Social networks allow citizens to 'meet' several people having similar interests and points of view in various aspects of life. Social networks have a good impact on changing mobility habits, but they must be accompanied by tracking of trips and "gamification".

\subsubsection{The Project ISUMO (Incentivized SUstainable MObility) (Spain, Portugal)}

The ISUMO project has been developed in Jaen (ES); within the project a web platform has been developed, which, as shown in Herrador et al. [22], integrates some metaservices (such as Geographical Information Systems), several ICT services and a QR code system connected to electric mobility.

The platform is very powerful in monitoring second by second the citizen trips. Indeed some citizens pretend to travel by bike, while in reality they perform their trips by car. The ISUMO project platform not only provides rewards, but it also monitors the user multimodal transportation trips and measures $\mathrm{CO}_{2}$ emissions.

\subsubsection{The Project MobiMart/Mimosa}

This project is one of the first application test of Mobility Credits (Dziekan et al. [23]). Mobility Credits were tested in several scenarios: Bologna, Funchal, Gdansk, Tallinn, Utrecht).

The application of Mobility Credits to bicycle trips involved some volunteer citizens, who allowed the detection of their trips for two weeks. This project was not very successful because only a small number of users were involved.

\subsubsection{The Project NURIDE (U.S.)}

In this research project, it was developed one of the most important rewarding systems applied to carpooling, which has created a network of over 176,000 users, who, by performing shared trips, gained credits and scores to spend in shops. The NURIDE project receives funding by the American government but also by commercial activities, which pay every time a $\mathrm{v}$ ehicle registered to NURIDE passes in front of their shops. Each registered user provides to the platform all details about the trips that he is going to perform, but, differently from the ISUMO platform, the system is 
not able to verify the truth of the information provided by the users.

\subsubsection{The Project 2MOVE2 (Tel Aviv, Israel)}

This project has involved a pilot application of 13 weeks (Barsky and Galztur [24]) and used an app for smartphone (AlterNativ) and social networks. It was required to the project participants to answer to a questionnaire about their socio-economic attributes and about their mobility habits and preferences. The AlterNativ app, developed in the project, is capable to both automatically classify the transport modes travelled by users, and to detect when a u ser change transport mode. This app embeds also GIS data, such as bus stops and railway stations.

\subsubsection{The EMPOWER Project}

Funded by the Horizon 2020 programme, it is based on four living labs (Milton Keynes, Enschede, Gothenburg and Helsinki) where new tools and business models are tested.

In the Milton Keynes Living Lab, actions are introduced to disincentivize the use of the bicycle and of public transport.

In Enschede, the app Smart is used to monitor and reward the usage of the bicycle.

In Gothenburg, people living in the same flat have access to a set of shared electric cars; moreover, it is tested an on demand last mile freight delivery system which uses electric vehicles.

Finally, in Helsinki some measures to incentivize the use of public transport and of the bicycle are tested.

All Living Labs are setting up a $\mathrm{n}$ Empower Toolkit [30], which it is composed of: a database of rewards; some mobility services to distribute rewards to citizens; a method that allows the cities of monitoring benefits and impacts gained from the rewarding actions.

\subsubsection{The MoveUs Project}

The MoveUs project develops an idea similar to the Good_Go platform, it integrates data provided by multiple sources to reconstruct the real time congestion on the roads, but it provides also other services, such as travel planners [26].

The project results are the app MoveUs and a series of API of the platform, which however are not freely available. The disadvantage of MoveUs is a too complex architecture, jointly with the fact that it is not open source.

\subsection{ITS Technology for Rewarding Systems} Many online tools, apps, ITS technologies embedded in web platforms were developed, which are aimed at improving the quality of travel of commuters in congested cities and at reducing the social costs of mobility, by encouraging sustainable mobility behaviors using rewards.

The technical term for such technologies is CAPTOlogy, acronym of Computers As Persuasive TecnOlogy: this is becoming a new field of research since years 2000 [21].

Apps for smartphone are some of the most important platforms to modify travel behaviours [28]. The apps for smartphone could be simply applications which incentivize the safe and ecological driving or also apps which require the daily user trips diary, using also GPS data.

Stopher et al. [29] shows that smartphone apps collecting data from GPS have a high potentiality in reconstructing user trips.

\subsubsection{The TomTom Traffic Index}

Common requirements, of ICT products for mobility services, are big data systems, which are coupled with data mining, data analytics and decision support intelligence, and are based on data collected from: ITS sensors, public administrations, social media, participative portals, personal devices and other communication infrastructures. The availability of localization sensors to the mass public is crucial to build big databases, and this enables the possibility to perform analyses not possible in the past. An example of this new opportunity, provided by the spreading of sensing technologies, is the 'TomTom Traffic Index', developed by TomTom as a product of locationaware mobile apps and connected devices. This index is based on 19 trillion data points, collected over nine years from $390 \mathrm{c}$ ities, and it allows to build a ranking of the most congested cities in the world. This is a relatively old issue, but before the wide diffusion of GPS sensors in the smartphone, it wouldn't be possible to get the adequate amount of information, neither for a world leader in consumer market of GPS enabled devices.

\subsubsection{The MVMANT Project}

The MVMANT project [14] represents an example of Mobility-as-a-Service (MaaS) solution; it became well known after UBER app, as it is integrated with taxi services. The project is based on: a $m$ achine learning mobility demand and logistic optimization, 
and on a city loyalty platform to engage and reward customers with free trips. But only car-based mobility (e.g. car sharing, car pooling) is supported, while commuters prefer to use also other transport modes [15]. In addition, the ICT components, for the provision of information and services to citizens by mobile apps, have to be: totally transparent to the service providers, either public administrations or private companies; and flexible enough to be scalable to the fast growing demand and expandable to integrate further commercial opportunities.

\subsubsection{The EMPOWER Project Solutions}

Nowadays, some solutions fulfilling these requirements are already available. Most of them are Software-as-a-Service (SaaS) ones, based on monthly or annual fee plan; for example the solutions developed within the project EMPOWER: Smart, CommuteGreener and ZWITCH. All of them run on the Mobility Service Infrastructure (MSI), which has been developed in the project [17]. The project has been applied to three living labs: Helsinki, Gothenburg and Enschede. The platforms deployed for the Living Labs are affected by complexity and fragmentation, probably due to the use case implementation, which is influenced by local needs and local culture; therefore, the platforms implementation and transferability are very difficult.

\subsubsection{The myEPPI Platform}

From the experience of Softeco Sismat and of the Municipality of Genoa, in the MoveUs project [26], another platform, myEPPI, has been developed, which comprises several ICT tools specifically tailored for citizens and stakeholders [19]. MyEPPI's ICT tools are used to inform the citizens, promote the incentives, measure the citizen behaviours and distribute the incentives. Thanks to a comprehensive Data Model it is possible to define the behavior that the users should follow to achieve the goals. But MyEPPI has still restricted access and limited documentation.

\subsubsection{The Km4City Platform}

Currently only Km4City [27] represents an open source smart mobility and smart city management alternative, but it is still at a prototypal stage as a product of 'SiiMobility' [31], an Italian strategic project funded by University and Research Ministry in 2016, in the area of Terrestrial Transportation and Mobility [33]. This platform enables technologies for smart cities and mobility: big data systems for decision support, monitoring interface, ticketing.

\subsubsection{TripZoom}

This app has been developed within the project SUNSET [30]. This app has been developed to incentivize sustainable trips and to share information on them. TripZoom gathers detailed information on trips performed by each user. From these data, TripZoom provides information on the most sustainable trips and provides rewards. TripZoom is also integrated in social networks such as Facebook and Twitter: each user can see his own mobility profile and compare it with the mobility profile of his friends.

The TripZoom system is composed of:

- a web portal, which shows the main functionalities of the app and describes the SUNSET project; from the web portal it is possible to install the app;

- the smartphone app, which can work in background using the GPS and the accelerometer sensors embedded in the smartphone;

- a city dashboard: it allows to public administrations to add rewards and manage the assignment of credits.

\subsubsection{TravelWatcher}

This app has been developed in the i-Zone project in Enschede, with the target of decreasing the traffic in the peak hour by $5 \%$. This app comprises a module which collects all real time data about traffic, by sensors installed on the field and by the app, and about meteorological conditions.

This app works in background and monitors user trips; it automatically detects transport means used, the places where the user has been, the most used paths, and finally calculates the environmental footprint of the user mobility habits.

\subsubsection{ViviBici (Italy)}

This system is based on a free app which monitors by GPS the trips performed by the users. If users travel by bike, they collect scores, called ' $\mathrm{km}$ Voice': if users have a COOP Voce SIM they can convert these scores in MB of COOP Voce traffic.

But this app is not capable of detecting the transport mode, therefore the user could travel by car and tell the app that he has travelled by bike and receive the corresponding reward.

\subsubsection{Other Apps}

The Driving Score app allows each user to monitor by GPS all trips performed by his own vehicle and 
to receive scores if his way of driving is 'green'. Other similar apps are Flo and Aviva Drive.

The Travel Smart Reward app has been developed within the Travel Smart Rewards programme in Singapore. This app monitors the use of public transport, and it rewards users especially if they travel by public transport in peak hours.

The ViaggiaPlay\&Go app has been developed in the cities of Rovereto and Trento, to incentivize sustainable mobility. Every week rewards offered by local companies are provided to users, according to the user mobility habits.

\subsection{Gamification}

"Gamification" means applying a game approach to a non-game context. It could be a useful tool to change user mobility habits, because it could transform a boring everyday action in a game. Some examples of gamification are following herewith.

\subsubsection{The Chromaroma Project}

Such a project was based on the London Oyster card and it is applied to commuters. It has changed the commuter trips into a competition, as it rewards players who perform their trips during off-peak hours, by bicycle or on foot.

\subsubsection{The Travel Smart Rewards System}

This system, already analyzed in this paper, contains gamification elements connected to rewards. Indeed, each month a competition takes place, where two users are extracted and receive further rewards. The probability of being extracted is proportional to the number of scores that each user has gained from his mobility habits.

\subsubsection{The app Commuter Greener}

This app has been developed by the Volvo group, and it is similar to the others previously described: the rewarding system is based on the trips detection by GPS and on the possibility to insert the transport mode used. Each registered user can receive notifies by e-mail on the number of scores gained, and can collect badges, i.e. progressive goals which identify the level of sustainability reached.

\subsubsection{The Mobi System}

The Mobi project, funded within the Intelligent Energy Europe programme and which began in 2013 and ended in 2016, has developed a system aimed at achieving the modal shift by gamification. An on-line game on sustainable mobility was implemented and rooted on the experience of the From5To4 commuter challenge game (F5T4).
Users were incentivized to perform more intelligent trips by means of competitions with own co-workers or friends. This game has increased the percentages of sustainable trips from $58 \%$ to $80 \%$, and the usage of private car has decreased from $65 \%$ to $42 \%$.

\subsubsection{The $\mathrm{CO}_{2}$ Fit App (Germany)}

The $\mathrm{CO}_{2}$ Fit app measures the emissions of $\mathrm{CO}_{2}$ performed by each users, and it rewards, by the socalled Retcoins, those users which have adopted sustainable mobility habits. This app is similar to several others, in the sense that it detects the path followed by the user via GPS. However, the user is required of manually enter the chosen mode of transport.

\subsubsection{The La'Zooz App (Israel)}

The La'Zooz app has introduced a new virtual currency, called 'zooz', which is gained by offering a ride in car pooling and is spent to pay a ride in car pooling. This is a collaborative transportation web system. Each user who offers a ride inserts on the platform the path that he is going to follow, while each user who requires a ride can visualize on the app all existing ride offers. The system works in real time and allows multiple ride sharing steps in the same trips. The problem of such system is to gain a user critical mass capable of covering all time intervals and all geographical areas. A solution could be the introduction of the game effect: this platform simulates the creation of a network, where each user is encouraged by awards to create a connection towards a given area in the system.

\subsubsection{The STREETLIFE Project}

This research project aims at changing citizens mobility habits by using the following measures [32]:

- implementation of an info-mobility system on the existing mobility alternatives and on their impacts in terms of costs, time and environmental footprint;

- improvement of the public transport offer;

- promotion of sustainable trips through rewards.

Citizens are provided with an app, which detects their trips and provides personalized multimodal alternatives based on sustainable mobility systems, such as bike sharing, car-pooling or park and ride.

This app provides also 3D virtual environments, augmented reality and some gamification elements combined with incentives. Each game consists by a set of rules whose define its general logic: for example, the score collection and the badge collection rules. 
In the city of Rovereto (It) forty citizens were involved in this project and tested the app Viaggia Rovereto for 5 weeks. At first glance, the user simply had to familiarize with the app, and contemporarily the app registered the user mobility habits. In the second phase, the app provided recommendations on the paths followed by the user, as well as more sustainable alternatives. The third phase consisted of a 2-week game. Three typologies of scores are provided: the 'green' scores related to $\mathrm{km}$ travelled by sustainable transport modes; the 'health' scores, related to kms travelled by bike or on foot, and the 'Park\&Ride' scores. At the end of the game, each participant receives a certificate with related scores, badges, and all the information on the trip modes.

\subsection{Artificial Intelligence Applications}

Artificial Intelligence (AI) can be defined as follows [36]: 'the science of making machines or systems do things that would require intelligence if done by men'. Artificial Intelligence has been defined by the European Commission as follows: 'Any machine or algorithm that is capable of observing its environment, learning, and based on the knowledge and experience gained, take intelligent actions or propose decisions'; and: 'Systems that display intelligent behaviour by analysing their environment and taking actions - with some degree of autonomy to achieve specific goals'. One of the main tools used in artificial intelligent is neural nets [36].

AI is being used in several transport fields: autonomous driving (driverless cars), driver behavior modelling, models which can forecast following of traffic signals by the driver, traffic network analysis and journey planning and optimizing, prediction of jams. Another application of $\mathrm{AI}$ is the short-distance ridesharing platform Uber, which uses AI techniques in all aspects of its services, from matching riders and drivers to vehicle route optimisation [37].

AI has been applied to some platforms described in section 2, in particular: the MVMANT project platform, TripZoom and TravelWatcher. A further application of AI to rewarding systems is the platform proposed by SOMOS and Neosperience [38]. The platform creates a 'city mobility brain'; in particular: it allows the monitoring (by smartphone) of user mobility habits; it forecasts user trips; it analyzes the impacts of new mobility management schemes. One of the application fields of this platform concerns the rewarding of sharing mobility: a specific module of the platform optimizes in dynamic shared trips according to the users requests/ bookings. The interaction with other modules of the platform, such as those dedicated to conventional public transport, allows to dynamic planning and management of multimodal trips.

\section{The Good_Go Rewarding Project}

The general project idea is to join services for private bikes (and the shared ones, also) with a social rewarding platform, called GOOD_GO, to increase sustainable mobility in the city. Then, it integrates hardware and software development with innovative measures regarding transport demand management and, mainly, with rewarding measures.

Firstly, a platform was developed to take data mainly from an app for smartphone and a service for private/sharing bikes, based on a RFID low-cost equipment, capable of:

- discouraging the bikes theft, through the development of "secure areas" where bicycles could be parked safely: if a bike is stolen, an alarm signal, directed to the bike owner, to all other clients of the platform, and to the police, is activated with a local acoustic alarm;

- allowing, in case of theft, the recovery of bicycles thanks to mobile detectors provided to policemen and parking enforcement officers.

Moreover, in order to increase the sustainable mobility 'incentive power', the platform develops a social space where people can: denounce the theft of their bike, post any information about events or any other news related to sustainable mobility, and participate to a competition based on po ints collected from the monitoring of their own daily trips. Actually, it is present a smartphone app able to monitor the user's trips and to provide some credits which could be spent in a rewarding system.

The rewarding management platform, named Good_Go and its first observed results of the real test case performed in Livorno city, are presented in the following sections.

\subsection{The Good_Go Platform}

Analysing the products developed and tested during the aforementioned rewarding existing projects, one can infer that:

- the mobile app is a fundamental tool for any sort of initiative in this field, whereas the web app should consist in the portal mainly aimed to manage the content provided by the service provider to the engaged community;

- the ICT system has to be able to ingest and process a relatively limited sort of data, 
related mainly to GPS tracks, but predisposed to provide a $\mathrm{v}$ ery wide range of feedbacks, based on relatively simple processing;

- the most appreciated products include decision support systems, at least for provisional services in deferred time.

Those previous experiences also taught that to attract more users and to be effective in changing mobility behaviour with citizen categories different by age, interests and social classes, at least three elements are fundamental:

- to promote a multi-modal approach for daily mobility;

- to engage different type of "contributors", i.e. enterprises and service providers able to manage different sort of economic advantages, including discounts on goods, services and even local taxes;

- to propose the services using a g amification approach, and dominant link to social networking, environmental awareness, safety, health and wellbeing in general.

The entities resulting more interested in contribute to this sort of initiates are public administration, mostly at municipal level, public transportation companies, sharing mobility service providers, insurance companies. It is worthwhile of reminding that, for an effective involvement of a contributor either public or private entity, the crucial task is to be able of analysing the real scope he wants reach to satisfy through the ICT solution, placed in a winwin perspective, for both the citizens user and the provider. This because the platform success depends primarily by the resources the latter spent in its initial stages. Within the project scope, the rewarding mobility prototypal platform will integrate only a su bset of features and options. A diagrammatic representation of main components constituting the Good_Go platform is depicted in Figure 1.

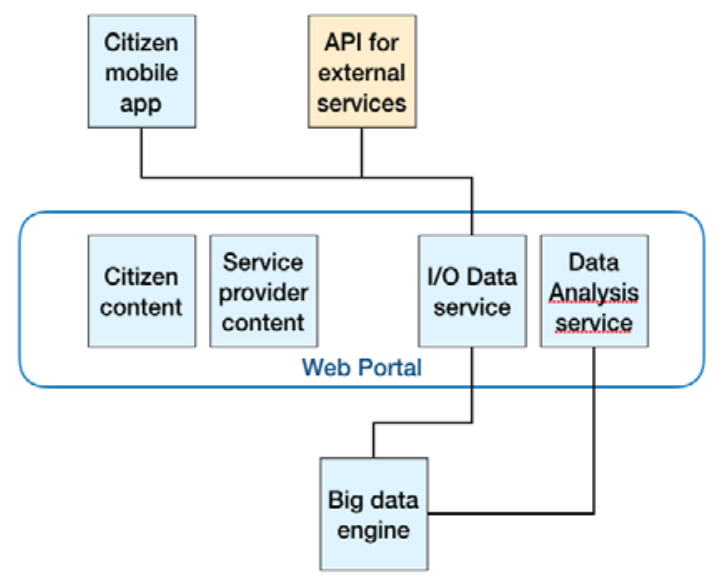

Fig. 1: GOOD_GO platform framework
The main differences among Good_Go and the other Smart Mobility platforms reviewed so far are:

- the platform is entirely developed and based on Open Source software (see graph in figure 2) that's to say Geoserver and MapStore for the GIS component and PostgreSQL for the Database component;

- the platform offer community-based functions to help users to find back their bicycle in case of theft and, optionally, to register and integrate the RFID based anti-theft system specifically developed within the project (as detailed in [33]).

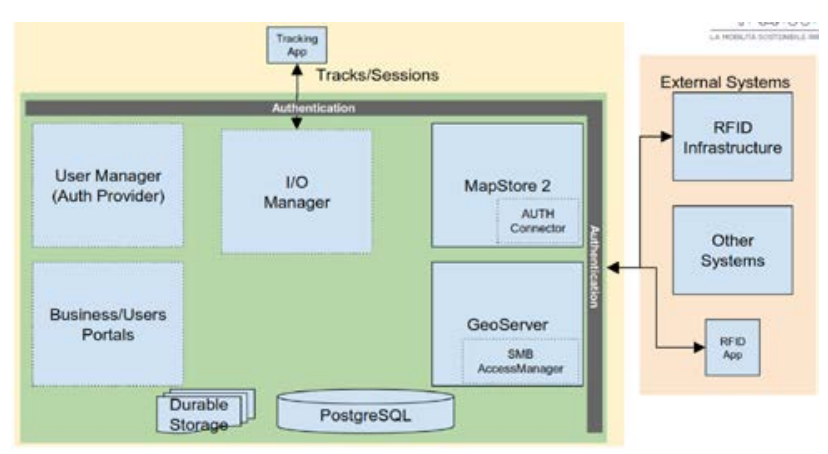

Fig. 2: The GOOD_GO platform general software framework.

The citizen, after the registration to the web portal, will have access to the mobile app to join the rewarding competition they are interested/involved. The platform allow (by a back-end service) to organize multiple mobility rewarding competitions at different hierarchical and geographical scales: for examples a race within the whole citizens of a city (big scale), a competition for university workers or students (medium scale), a co mpetition within classes of the same educational institution or within workers of the same company (little scale). Figure 3 shows three competitions actually ongoing in the city of Bolzano, Pisa and Florence.

The competition participant has also the possibility to save a personal profile including description and pictures of his own bicycle. 


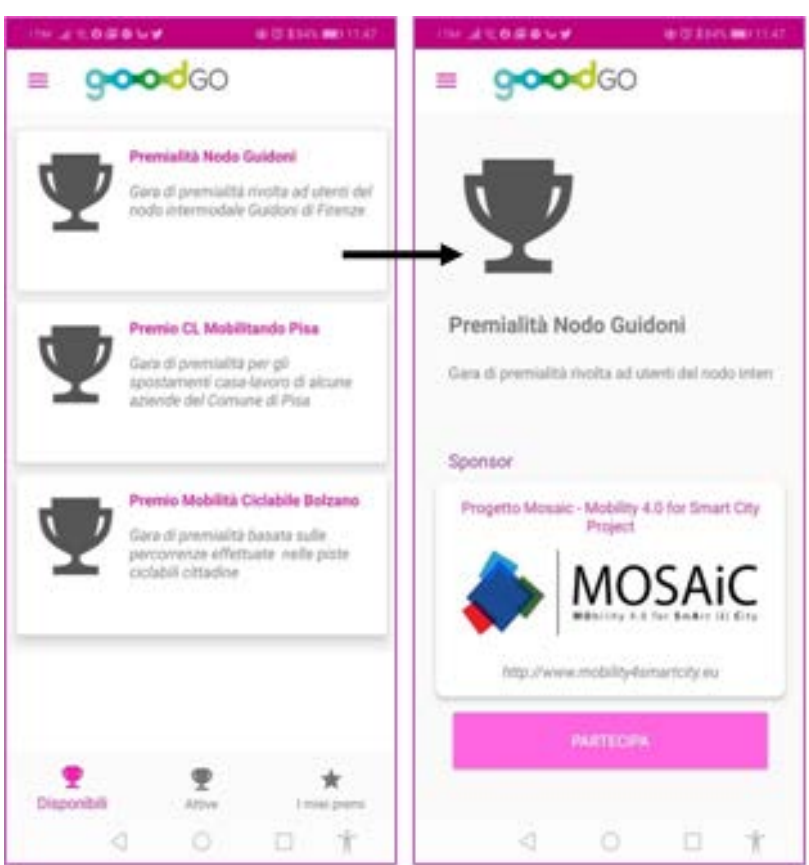

Fig. 3: The mobility rewarding competition (the competitions opened, on left; the participant registering web form, on right).

On the base of mobility behaviour monitored (a tracking activity is activated by the App allowing users to insert the start and end phase for each trip and inserting directly the transport mode used, as showed in figure 4), the user will gain badges allowing discount for public transport subscriptions or other products. Once the user will reach an adequate badge amount will have chance to request an offered discount, or to accumulate more badges to access at a superior discount level.

During the tracking phase (Fig. 5) many indices are automatically calculated and specifically:

- Mobility cost indices based on a transport cost model:

- vehicle depreciation cost;

- fuel cost;

- operational costs;

- time costs.

- Hearth indices:

- consumed calories;

- benefits index (probability reduction of cardiovascular diseases from the HEAT model, i.e. Health Economic Assessment Tool, for cycling and walking).

- Atmospheric emissions indices for $\mathrm{CO} 2, \mathrm{CO}$, NOX, PM10, SO2 pollutions:

- quantity of emissions avoided;

- quantity of emissions released.

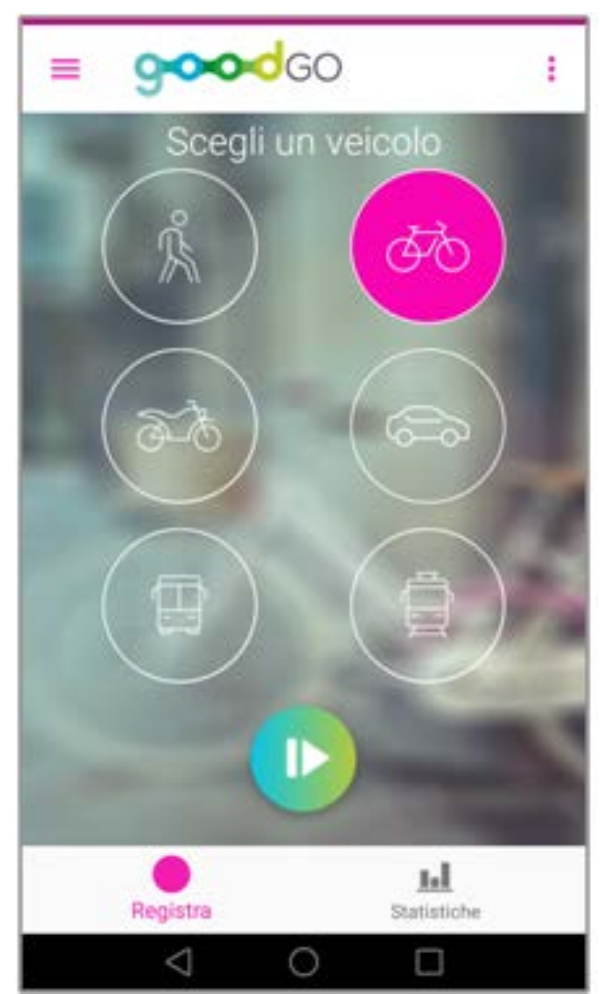

Fig. 4: The App screenshot for joining both tracking phase and transport modes used.

In case of theft of his bike, the user can immediately send a geocoded notice with all description and pictures of his bike he previously registered. The members of Good_Go community will have the possibility to reply it in case of retrieval, giving the position and a short note.

When the participant is using also the RFID antitheft system, the RFID code is both marked in a "blacklist", and it is notified to local public authorities which are provided with a RFID reader able to detect and recognize the stolen bike during their routine activities.

Moreover, in this last instance the bicycle owner will be automatically notified in case of retrieval. According to the level of publication chosen by the user, his/her history can be shared with friends and public, for a community contest regarding distance run, wealthy and contribution to air pollution reduction. 


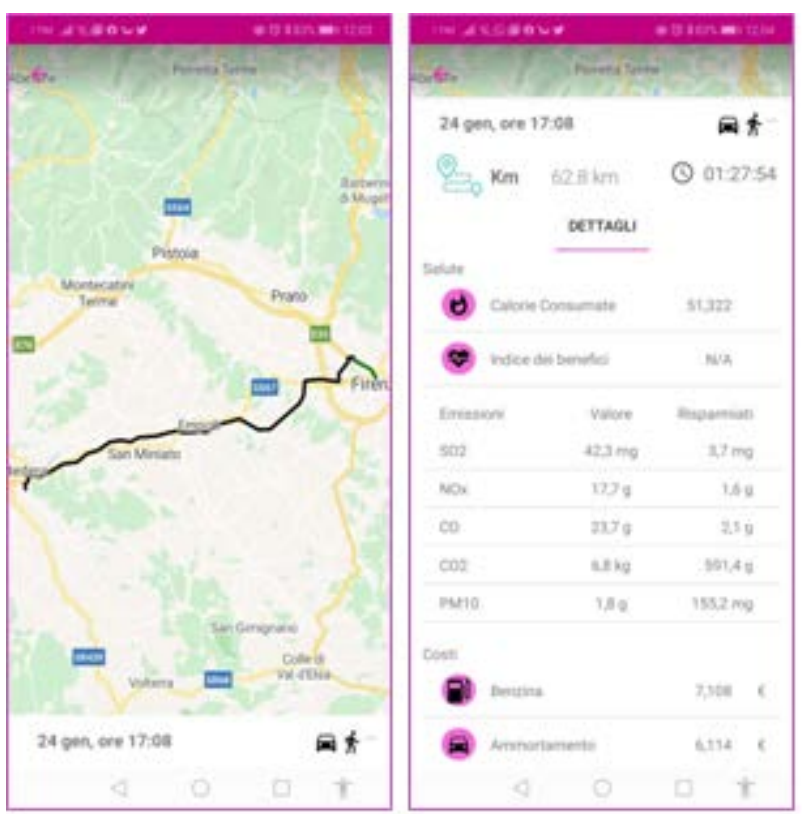

Fig. 5: Screenshots of the modal tracking phase and its calculated indices.

The reward provider, i.e. the local transportation service enterprise, will have access t o a sp ecific section of Good_Go portal, in order to manage and publish their discount campaign. This specific content management web tool will allow to easily managing the value for money of the discount and the categories of user that will have access to each offer, according to their profile and mobility habits, other than the offer expiration. Moreover, they will chance to monitor in a dashboard basic result of track data processing and aggregation, useful to improve their service offer and timetable, as such as follow the evolution of habits changes within the community engaged in the initiative.

In addition, the choice of the prototypal application to be carried out in the city of Livorno (Italy), arises from the need to simplify and study a prototype easily replicable in other urban realities, even in the search for potential users. Actually, it is not always possible to obtain a set of user license plates, from which could be extracted a 1 ist of commuters, otherwise to have resources for making interview surveys on a population sample.

In our instance, we have set up a multimodal connection between the bicycle system and the local public transport system allowing to identify potential customers of the public transport system with ad hoc rewards. For example, it is possible: to offer single tickets at a reduced price for those who never use public transport but perform compatible routes, or to provide subscriptions to those who only occasionally use public transport. In this way, a reward is offered to everyone, since public transport is attractive for everyone, while a h igh level of reward personalization is maintained and the reward system is simplified as much as possible, making it easier its broadcasting to people. On the other hand, we are contacting the institutional actors and stakeholders, able to help us in the dissemination of the prototype launch event, scheduled for the beginning of 2018: the Chamber of Commerce, the Municipality, FIAB (Italian Bicycle Friends Association), etc. This way, the whole population will be involved. In addition, it will be tested: the attractiveness that this simple system can have to citizens, and the attractiveness of monitoring services, such as R FID, together with the other services offered. They will be experienced: the citizens' response will be checked not only on the effects of rewarding at urban level, but also on the attractiveness of a rewarding offer to the population.

\subsection{Livorno Test Case Results}

The test carried out in the city of Livorno lasted about $4 \mathrm{~m}$ onths at the end of 2018. During such period, it has applied both the rewarding system and the bike-anti-theft services. The resulting data shows about 3.5 thousands individual mobility paths with of 1,000 subscribers as total. At transport mode level, these latter data are distributed in a $\mathrm{v}$ ery asymmetrical way, as shown from Figure 6.

During the test has been monitored the transport emissions and cost and the percentage of bike and foot trips give very high value of avoided emissions (see Table 1).

Table1: The emissions indices

\begin{tabular}{|c|c|c|}
\hline Pollutant & $\begin{array}{c}\text { Realesed } \\
\text { emissions }\end{array}$ & Avoided emissions \\
\hline SO2 (mg) & 561 & 4,885 \\
\hline NOx (g) & 338,696 & $1,939,090$ \\
\hline CO2 (kg) & 89,826 & 786,627 \\
\hline CO (g) & 476,319 & $2,758,680$ \\
\hline PM10 (mg) & 26,997 & 201,907 \\
\hline
\end{tabular}




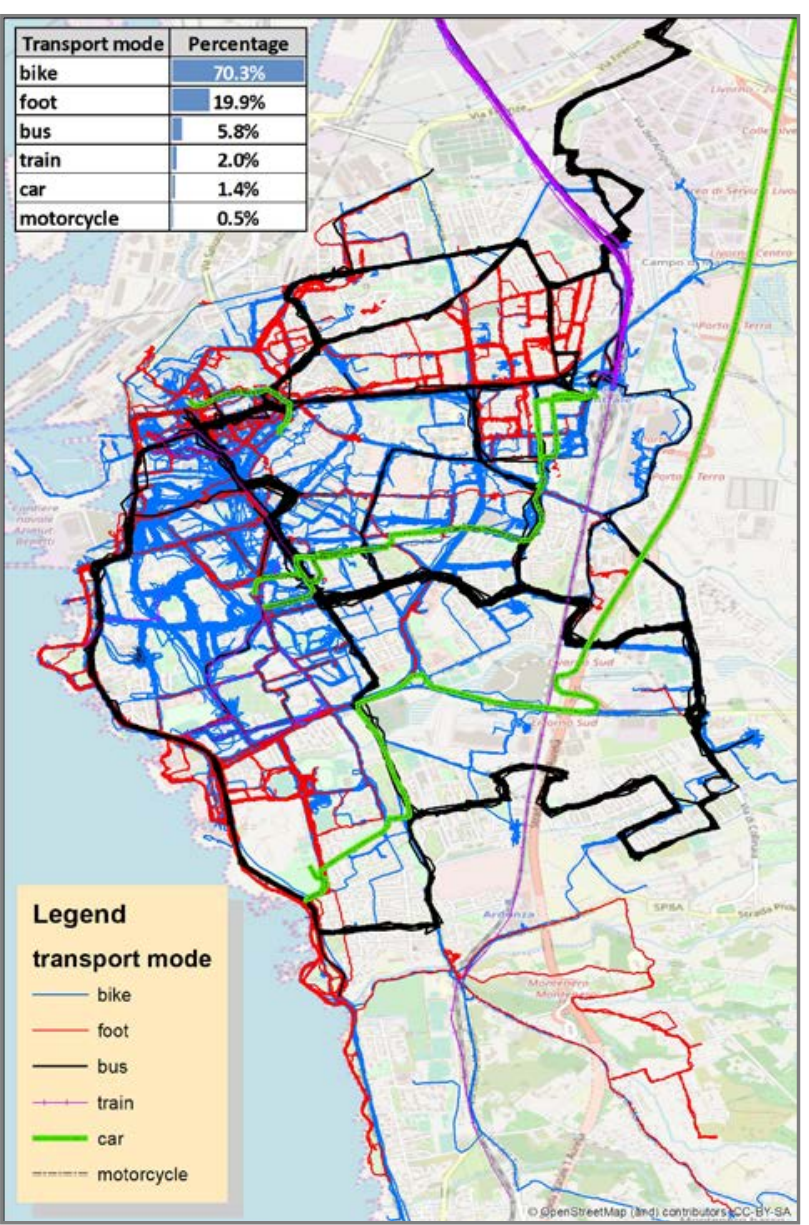

Fig. 6: The modal tracking phase and the calculated indices.

The efficiency and the impact due to the coupling of the reward system and the theft disincentive system. In fact, the first response in the test came from those who were already cyclists and interested in protecting their bikes from theft. Of these bikes, almost $50 \%$ then used the reward system and won the prizes put into play, making up almost the total sample of those who participated in the reward system. This means that the reward system alone has not been able to attract many users but its coupling with a second service for private bikes, very 'felt' by the population, has increase its users and has made it possible to have an important sample and monitor its mobility. Nowadays, the most monitored mobility by the platform is the bicycle and pedestrian one, as also illustrated in Figure 6. This is prompting us to experiment with other incentive solutions allowing us to expand the users sample and to monitor even those who move by car.

The actual research issue regards the integration of the monitored data with data coming from the territory by means of Artificial Intelligence
Algorithms so to extract relation between land and meteorological features and mobility behaviours (some of the techniques applied have described in [34] and [35]).

\section{Conclusions and Future Research Developments}

Rewarding policies have proven to be significantly more effective measures than restrictions to achieve a modal shift from private car to more sustainable transport modes. Several rewarding systems have been tested in the field, but they have been successful only when an adequate participation of citizens has been achieved.

Many apps and web platforms have been developed to manage such systems, in particular to track the paths followed and the transport modes used by citizens when performing their trips: this is fundamental in order to calculate the amount of reward.

On the ground of future rewarding policies, the main goal of the Good_Go project is to develop a real multi-modal reward management system, which is able of introducing several incentive tools for sustainable mobility, based on the following types of measures:

- punctual measures, e.g. reward for crossing given road sections;

- linear measures, e.g. reward for travelling along given roads;

- areal-based measures, e.g. rewards for parking or travelling in a specific area.

All these incentive systems can differ in the level of rewards/credits provided, and can vary according to the time of day, the travel direction (in-out), the journey performed, the type of vehicle, etc.

An other future development of the Good_Go research project consists of the completion of the multimodal platform with the possibility of setting up rewarding strategies by the administrations, reconstructing a real visual language / wizard to set and customize the rewarding policies. This multimodal system will be linked to a MarketPlace with an increase in the economic viability of the project as the companies subscribed will pay an annual fee (quite similar to the Nuride system quoted above).

In addition, a real and proper wizard will be implemented, for the guided upload of the data about the urban reality under consideration, which is a very important and challenging step for the sustainability of the project. Such a wizard will be 
conceived to allow of uploading in the platform all the features related to each local territories, features useful to verify the transport mode indicated (for example uploading cycle-lines or public transport stops) from users during the tracking session and to introduce other rewarding policies (like cordon park\&ride areas and others). In fact, all existing and tested systems are, currently, valid only for single realities and do not contain automatic setup elements for their application to other cities. Within this development, they will be integrated a system able: to monitor transport modes chosen to perform the displacements, and to analyze their possible replacements with more sustainable transport modes, in order to activate the related rule like a Travel FeedBack Program.

\section{References:}

[1] European Commission, Statistical pocketbook 2016. Available at: https://ec.europa.ew/ transport/facts-fundings/statistics/pocketbook2016_en.

[2] European Commission, 2013. Communication from the Commission to the European Parliament, the Council, the European economic and social committee and the committee of the regions, $\operatorname{COM}(2013) 913$, Bruxelles, 2013.

[3] Petri M., Frosolini M., Pratelli A., Lupi M., ITS to change behaviour: A focus about bike mobility monitoring and incentive - The SaveMyBike system. EEEIC 2016 International Conference on Environment and Electrical Engineering, 2016.

[4] Pratelli A., Petri M., Farina A, Lupi M.. Improving bicycle mobility in urban areas through ITS technologies: the SaveMyBike project, Advances in Intelligent Systems and Computing, 2018.

[5] EPOMM-European Platform on M obility Management, Rewarding behaviour change, 2017: http://www.epomm.eu/newsletter/v2/eupdate.ph $p ? n l=0317$ 2\&lan=en

[6] Dogterom N., Ettema D., Dijst M., Tradable credits for managing car travel: a review of empirical research and relevant behavioural approaches, Transport Reviews, vol. 37(3), 2017, pp. 322-343.

[7] Tillema, T., Ben-Elia, E., Ettema, D., Road pricing vs. peak-avoidance rewards: a comparison of two Dutch studies. Proceedings of the $12^{\text {th }}$ World Conference on Transport Research, Lisbon, 2010.
[8] De Palma A., Proost S., Seshadri S., Ben-Akiva M., Tools versus Mobility Permits: a comparative analysis. Report prepared for the French Ministry of Ecology, Durable Development and Energy, 2016.

[9] Weitzam, M. L., Prices vs Quantities. Review of Economic Studies, Vol. 41(4), 1974, pp.477491.

[10] Parag, Y., Capstick, S., Poortinga, W. Policy attribute framing: A comparison between three policy instruments for personal emissions reduction. Journal of Policy Analysis and Management, Vol. 30, 2011, pp. 889-905.

[11] Bae C-H C., Bassok A., The Pudget Sound (Seattle) congestion pricing pilot experiment. In Bae, C-H C., Richardson H. W. (eds.), Road Congestion Pricing in Europe: Implications for the United States. Edward Elgar, Cheltenham, 2008.

[12] Khademi E., Timmermans H., Borgers A., Temporal Adaptation to Rewarding Schemes: Results of the SpitsScoren Project. Proceedings of the $17^{\text {th }}$ meeting of the Euro Working Group of Transportation, EWGT2014, 2-4 July 2014, Seville, Spain.

[13] Ettema D., Verhoef E., Using Rewards as a Traffic Management Tool: Behavioural Effects of Reward Strategies. Proceedings of the $11^{\text {th }}$ International Conference on Travel Behavior Research, Kyoto, 16-20 August 2006.

[14] MVMANT project website: http://www.mvmant.com

[15] Neckermann L., Smart Cities, Smart Mobility: Transforming the Way We Live and Work, Troubador Publishing Ltd, 2017.

[16] Bresciani C., Colorni A., Lia F., Luè A., Nocerino R., Behavioral change and social innovation through reward: an integrated engagement system for personal mobility, urban logistics and housing efficiency. Proceedings of the 6th Transportation Research Arena, 18-21 April 2016.

[17] Vreeswijk J., Mobility Services Infrastructure (MSI). EMPOWER project, deliverable D4.1, 2015: $\quad$ http://empowerproject.eu/wpcontent/uploads/2015/09/D4.1deliverable.pdf

[18] Fuji S., Taniguchi A., Determinants of the effectiveness of travel feedback programs - a review of communicative mobility management measures for changing travel behaviour in Japan. Transport Policy, Vol. 13(5), 2006, pp.339-348

[19] MyEPPI website: http://www.myeppi.com

[20] Tertoolen G., van Kreveld D., Verstraten B., Psychological resistance against attempts to 
reduce private car use. Transportation Research Part A: Policy and Practice, Vol. 32(3), 1998, pp.171-181.

[21] Fogg B.J., Persuasive Technology: Using Computers to Change What We Think and Do. $1^{\text {st }}$ edition, Morgan Kaufmann, S. Francisco (U.S.) 2002

[22] Herrador M., Carvalho A., Feito R., An Incentive-Based Solution of Sustainable Mobility for Economic Growth and $\mathrm{CO} 2$ Emissions Reduction. Sustainability, Vol.7, 2015, pp.6119-6148.

[23] Dziekan K., Liguori G., Ramazzotti D., MobyMart-A pilot test on sustainable mobility credit system in Bologna. Proceedings of Mobil.TUM 2011, International Conference on Mobility and Transport, 7-8 April 2011, Munich.

[24] Barsky Y., Galtzur A., Integration of Social Inventives Aimed to Promote Behavioural Change. Civitas Tel Aviv-Yafo report, WP 8, 2016.

[25] The EMPOWER project toolkit website: www.empowertoolkit.eu

[26] MoveUs project website: http://www.moveusproject.eu

[27] Km4City website: http://www.km4city.org

[28] Wouter B., Koolwaaij J., Peddemors A., User behaviour captured by mobile phones. In: Communications in Computer and Information Science, vol. 277, 2014.

[29] Stopher P., Clifford E., Swann N., Zhang Y., Evaluating voluntary travel behavior change: suggested guidelines and case $\mathrm{s}$ tudies. Transport Policy, vol. 16, 2009, pp. 315-324.

[30] Broll G., Cao H., Ebben P., Holleis P., Jacobs K., Koolwaaij J., Luther M., Souville B., Tripzoom: an app to improve your mobility behavior. Proceedings of the $11^{\text {th }}$ International Conference on Mobile and Ubiquitous Multimedia, MUM 2012, Ulm, Germany, December 2012.

[31] SiiMobility wbsite: http://www.sii-mobility.org/

[32] Kazhamiakin R., Pistore M., Marconi A., Valetto G., Using Gamification to Incentivize Sustainable Urban Mobility, Proceedings of First International Smart Cities Conference (ISC2), IEEE Xplore repository, 2015.

[33] Petri M., Pratelli A., SaveMyBike-A Complete Platform to Promote Sustainable Mobility Lecture Notes in Computer Science (including subseries Lecture Notes in Artificial Intelligence and Lecture Notes in Bioinformatics), 2019.
[34] Petri M., Pratelli A., Barè G., Piccini L., A Land Use and Transport Interaction Model for the Greater Florence Metropolitan Area, Lecture Notes in Computer Science (including subseries Lecture Notes in Artificial Intelligence and Lecture Notes in Bioinformatics), 2019.

[35] Pratelli A., Petri M., Ierpi M., Integration of Bluetooth, Vehicle Count Data and Trasport Model Results by Means of Datamining Techniques: The application to the regional highway S.G.C. Fi-Pi-Li linking Florence to Leghorn and Pisa, Proceedings - 2018 IEEE International Conference on Environment and Electrical Engineering and 2018 IEEE Industrial and Commercial Power Systems Europe, EEEIC/I and CPS Europe, 2018.

[36] Šusteková D., Knutelská M., How is the Artificial Intelligence used in applications for traffic management. Proceedings of XXIII International Scientific - Technical Conference “Trans \& Motauto '15", Varna, 24-27 June, 2015.

[37] European Parliament, Artificial intelligence in transport. Current and future developments, opportunities and challenges, Brussels, 2019.

[38] Innovation Club website: http://www. innovationclub.it/aigamecitta/. 